\title{
Valorisation of frozen chestnut by-products: technological challenges for the production of gluten-free flour
}

\author{
Ana Borges $^{1} \cdot$ Catarina Fonseca $^{1} \cdot$ Filipa Carreira $^{1} \cdot$ Ivo Rodrigues $^{1} \cdot$ Marta Henriques $^{1} \cdot$ Ana C. A. Veloso $^{2,3}$. \\ António M. Peres ${ }^{4,5}$
}

Received: 31 July 2018 / Accepted: 23 November 2018 / Published online: 27 November 2018

(c) Springer Science+Business Media, LLC, part of Springer Nature 2018

\begin{abstract}
The industrial process of freezing chestnuts generates $55-60 \%$ of by-products. This study aimed to valorise these low-value by-products by producing high-value chestnut flour. Two flour production processes were evaluated, using raw (RCF) and cooked (CCF10, CCF30, CCF50) chestnut by-products during 10,30 and $50 \mathrm{~min}$. The highest production yield was obtained for RCF $(43.6 \pm 1.0 \%)$ followed by CCF10 (38.0 $\pm 1.0 \%)$. Regarding flour composition, CCF50 presented the smaller protein, fat, fibre and ash contents $(P<0.05)$. For colour, $\mathrm{a}_{\mathrm{w}}, \mathrm{pH}$ and sedimentation index, no significant differences were observed namely between RCF and CCF10 $(P>0.05)$. The CCF10 flour also presented the smallest particle size. The highest peroxide index was found in CCF50 penalizing its acceptance by consumers due to the evidence of rancidity, emphasizing that long time-periods of cooking must be avoided. Finally, up to 129 days of storage, under no temperature or lighting controlled conditions, all chestnut flours showed to be stable overtime.
\end{abstract}

Keywords Castanea sativa Mill · Frozen chestnut low-value by-products · Chestnut flour · Gluten-free flour · Chemical composition and quality

\section{Introduction}

Marta Henriques

mhenriques@esac.pt

$\triangle$ António M. Peres

peres@ipb.pt

1 Instituto Politécnico de Coimbra, Escola Superior Agrária; Cento de Estudos dos Recursos Naturais, Ambiente e Sociedade (CERNAS), Bencanta, 3045-601 Coimbra, Portugal

2 Instituto Politécnico de Coimbra, ISEC, DEQB, Rua Pedro Nunes, Quinta da Nora, 3030-199 Coimbra, Portugal

3 CEB - Centre of Biological Engineering, University of Minho, Campus de Gualtar, 4710-057 Braga, Portugal

4 Centro de Investigação de Montanha (CIMO), ESA, Instituto Politécnico de Bragança, Campus Santa Apolónia, 5300-253 Bragança, Portugal

5 Laboratory of Separation and Reaction Engineering Laboratory of Catalysis and Materials (LSRE-LCM), ESA, Instituto Politécnico de Bragança, Campus Santa Apolónia, 5300-253 Bragança, Portugal
Portugal is one of the main producers of sweet European chestnuts (Castanea sativa Mill.) [1,2]. European chestnut has been grown in Portugal for centuries for both wood and fruit production [3]. According to official data, in 2013, Portugal was the third largest producer of chestnut in Europe (EU 28) and the seventh worldwide, with an annual production of 24.7 thousand tones, and an orchard area of 35 thousand hectares [4]. The north of the country stands out as the main production region being the majority of the chestnut production exported, either as frozen or as fresh chestnut, being the remaining production for domestic consumption $[2,4]$. Thus, chestnut has a great economic importance, and according to statistical data, in 2015, 27.6 thousand tons of chestnuts were produced, reaching an income of $41 \mathrm{M} €[4]$. Indeed, chestnut economic value is increasing not only due to its nutritional quality as well as to the beneficial health effects [5]. Two of the most representative cultivars produced in Portugal are Judia and Longal since they present medium to large size, improved conservation properties and good organoleptic quality, being two of the most appreciated chestnuts cultivars from Trás-os-Montes [6]. Chestnut 
is a rich source of starch, with low protein and fat contents, being also a potential source of vitamins [7]. Besides the nutritional advantages, chestnut is a gluten-free fruit and therefore suitable for people suffering gluten-related disorders such as celiac disease, which treatment relies on absolute and lifelong dietary withdrawal of gluten [8]. Indeed, in the last years several works have reported the use of chestnut flour in the manufacture of gluten-free and functional food products, such as, bread, cookies, muffins, pasta, snacks and probiotic fermented milk supplemented with chestnut flour [7, 9-23]. In fact, since most of the gluten-free cereal products contain low amounts of health beneficial components, it may be advantageous to use chestnut flour due to its nutritional value [23]. Chestnut flour contains essential amino acids (4-7\%), relatively high amount of sugar (20-32\%), starch (50-60\%), dietary fibre (4-10\%), being also rich in minerals like potassium, phosphorous and magnesium [24]. In conclusion, the incorporation of chestnut flour in different types of foods showed in general a good potential for consumer acceptance, being seen as health promoting functional ingredients, especially for celiac disease patients [23].

Moreover, some studies pointed out that in several applications wheat flour may be substituted or its content reduced by using gluten-free flours, namely by chestnut flour, allowing to retain or increase the final overall food quality and sensory positive sensations [7, 9-11, 13, 17].

During the industrial chestnut processing (e.g., calibration, peeling and freezing), a large amount of waste material is generated, comprising broken, badly peeled, burned, and without proper size chestnuts, which represents $55-60 \%$ of the total frozen chestnut production. The poor visual and organoleptic characteristics of these by-products significantly penalize its use for novel food applications, reducing its market value in approximately 50\%. On the other hand, the price of highest quality frozen chestnut is about half the price of chestnut flour. So, the possibility of using chestnut low-value by-products for the production of high-value flour for human consumption turned out to be economically appealing and may enhance the environmental sustainability of the chestnut processing industry [5, 25]. The majority of the studies available in the literature deal with the evaluation of raw chestnuts or of chestnut flours obtained using the entire chestnut fruit and not the by-products arisen during the chestnuts industrial processing [26].

Therefore, this study intends to evaluate the feasibility of producing chestnut flour as a way to increase the economic revenue of low-value frozen chestnut by-products. Two production processes were studied (i.e., using either raw or cooked chestnuts by-products), being evaluated their influence on the overall process yield, physicochemical properties and quality stability during storage. In fact, chestnut processing (e.g., roasting, boiling, drying, pan, microwaving, osmotic dehydration, $\gamma$-irradiation, electron beam irradiation, radio frequency treatment, storage, extrusion, and candying procedures) as well as the different stages of industrial chestnut processing significantly affect the total phenol content, total antioxidant activity, phenolic compounds levels, as well as protein, fat, ash, moisture, organic acids contents, make the chestnut palatable, increase the shelf life, and improve the overall quality [16, 26-33]. However, the extent and trend of the changes (increase or decrease effect) highly depend on the type of processing applied but, some studies confirmed that cooked chestnuts are a good source of organic acids and phenolic compounds, possessing low fat contents, properties related with health benefits [31]. Moreover, roasting procedure contribute to the reduction of the anti-nutritional factors in chestnut [16]. Also, flours obtained by thermal processed chestnuts usually exhibit a significant decrease in light transmittance [26], foaming, and pasting properties together with higher gelatinization temperatures, lower enthalpies and reduced viscoelastic behaviour [16]. Finally, it has been shown that chestnut flour may be a natural source of specific bioactive components, allowing to establish, for example, appropriate nutritional therapeutic approaches to skeletal muscle atrophy [34].

\section{Materials and methods}

\section{Production of chestnut flours}

Chestnut flours were produced using as raw material industrial by-products of frozen chestnuts (including Longal and Judia cultivars), provided by Sortegel (Bragança, Portugal), which are mainly constituted by partially burned chestnuts with darker and harder parts, badly peeled, broken and rotten chestnuts. The chestnut shell was previously removed from the chestnuts during the burning industrial stage of the frozen chestnut production and so, they were not used for obtaining the flours. Until use, the low-value by-products were stored at $-18{ }^{\circ} \mathrm{C}$ in sealed plastic bags inside cardboard boxes, exactly in the same conditions they were stored in the company.

Different process configurations were designed to obtain 4 different types of chestnut flours: raw chestnut flour (RCF) and cooked chestnut flour (CCF10, CCF30 and CCF50). The boiling/cooking method was selected in order to simultaneously minimize the microbial deterioration of the chestnut by-products and also to improve the separation of the harder/ darker parts from the higher quality material of the chestnut by-products. 


\section{Raw chestnut flour}

In the preparation of RCF (Fig. 1a), the industrial chestnut by-products were taken from the freezer chamber, crushed (Tecator 1094 Homogeneizer, Sweden) to obtain homogeneous smaller pieces, and placed into a pilot scale tray dryer (STI-SDP, Portugal) with a drying chamber of $1.40 \mathrm{~m} \times 1.00 \mathrm{~m} \times 0.90 \mathrm{~m}$, equipped with 6 trays $\left(0.396 \mathrm{~m}^{2} /\right.$ tray). The drying process was carried out at $55{ }^{\circ} \mathrm{C}$ under tangential hot air convection at $1.5 \mathrm{~m} / \mathrm{s}$ and $30 \% \mathrm{RH}$. The drying temperature was defined according to the findings of Moreira et al. [26] that observed a significantly decrease in total starch content with increasing drying temperature (45, 65 and $85^{\circ} \mathrm{C}$ ). The higher size of the chestnut by-products was also taken in consideration and $55^{\circ} \mathrm{C}$ was used for drying. Afterwards, the dried chestnut by-product was milled using an electrical gristmill equipped with a granite millstone with $0.5 \mathrm{~m}$ diameter (Magager mod. 0.5, Portugal). The obtained flour was sequentially sieved using three different sieves ( $2 \mathrm{~mm}$ mesh; $1.5 \mathrm{~mm}$ mesh and $1 \mathrm{~mm}$ mesh) to separate the course part of the flour. The final RCF was stored in sealed transparent plastic bags at room temperature $\left(15-20^{\circ} \mathrm{C}\right)$ in dry conditions and without any special light care.

\section{Cooked chestnut flours}

For CCF the industrial by-products were taken from the freezer and cooked in boiling water during 10, 30 and $50 \mathrm{~min}$ (CCF10, CCF30 and CCF50) as shown in Fig. 1b-d, respectively.

In the case of CCF10 (Fig. 1b), after the cooking process the by-products were crushed using a potato masher, which turned out to be a difficult task due to the stiffness of the darker parts of the by-products. The mashed product was placed into trays and dried under the same conditions as RCF; being the darker parts of the mixture removed manually. The remaining dry material was ground (Moulinex A327R1 mincer, Spain). Two sieves, with $1.5 \mathrm{~mm}$ and $1 \mathrm{~mm}$ mesh, were used to separate the bigger grains (that usually include the darker parts due to their higher stiffness and milling resistance) from the smaller ones (lighter).

For CCF30 (Fig. 1c) and CCF50 (Fig. 1d) a chestnut puree was formed after boiling in the bottom of the pan. After separation this puree was dried as RCF and CCF10 flours. To avoid an inefficient drying process, the thickness of the product layer per tray was maintained smaller than $0.5 \mathrm{~cm}$. The dried puree was ground and a clear flour was obtained without dark particles. While in the case of CCF50, the by-products dark parts were completely separated from the puree during boiling, in the case of CCF30 the puree was only partially removed (Fig. 1c). In this case, after drying, the darker parts were manually removed and the remaining product was milled with a granite millstone. All the obtained CCF were stored in sealed transparent plastic bags in the same environmental conditions as RCF flour.

Chestnut flour production yields and material loss yields for each process configuration were assessed by mass-balances using $7 \mathrm{~kg}$ of chestnut by-product per batch, taking into account the minimum raw material mass required to run the granite mill ( $0.700 \mathrm{~kg}$ of dry by-products) and, further transposed to $100 \mathrm{~kg}$ of chestnut by-products.

\section{Flour compositional analyses}

Chestnut flours composition was evaluated according to Weende scheme being determined the moisture, crude

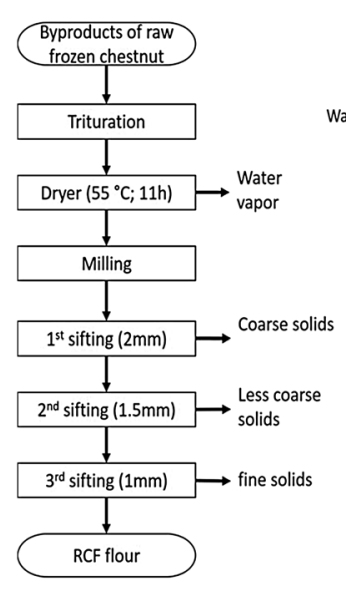

(A)

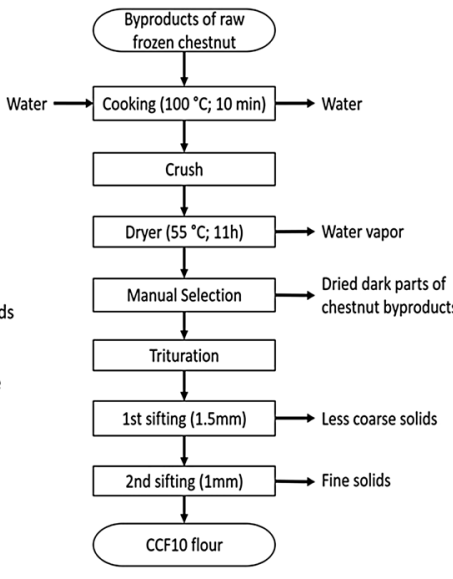

(B)
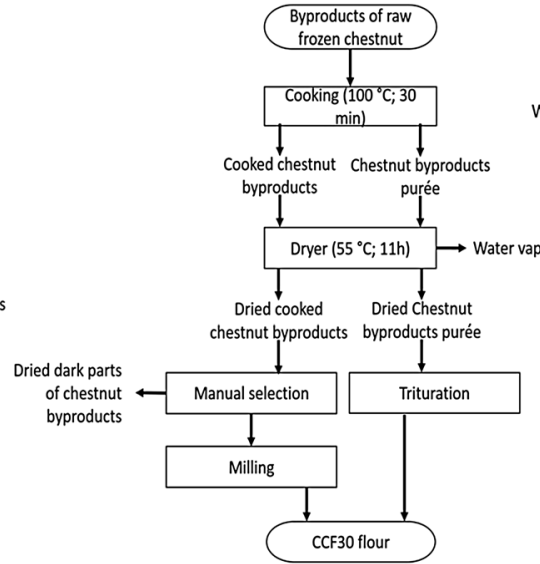

(C)

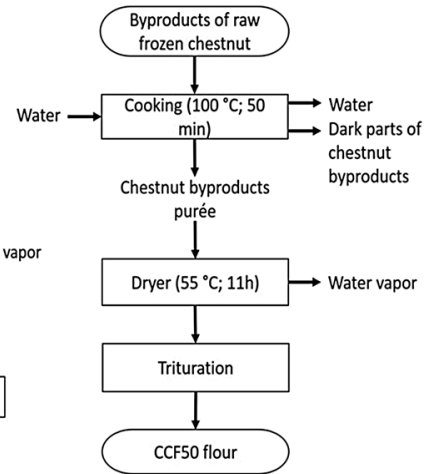

(D)

Fig. 1 Flowchart of the production of high-value raw and cooked chestnut flours from low-value frozen chestnut processing by-products: RCF flour production (a); CCF10 flour production (b); CCF30 flour production (c); and CCF50 flour production (d) 
protein, fibre, ash, fat and the nitrogen-free extract obtained by difference to the sample ( $\%$ in dry basis; i.e., db). Total solids, crude fibre and ash contents were evaluated by Weende method [35]. Crude protein was determined by Kjeldahl method 979.09 [36] and crude fat according to the Soxhlet method 920.39C [37]. All the analyses were done in triplicate and the results compared to the composition of two commercial chestnut flours purchase in local markets (coded as MT and MR).

\section{Flour quality evaluation}

The water activity $\left(\mathrm{a}_{\mathrm{W}}\right)$ was directly evaluated in samples using a Rotronic-hygroskop BT with a WA-14TH probe (Switzerland). $5 \mathrm{~g}$ of flour was placed in the equipment cell and allowed to stabilize for $1 \mathrm{~h}$ at $20{ }^{\circ} \mathrm{C}$ prior to the reading. $\mathrm{pH}$ determination following the method proposed by Hart and Fisher [38] using a pH meter (Hanna Instruments, model HI9025 with FC200 probe, Portugal). Colour coordinates were evaluated according to the CIE L*a*b* system using a Chroma Minolta CR200 colorimeter (Japan). The sedimentation index was assessed following the Zeleny sedimentation test [39]. Alcoholic acidity was determined according to IS:1155-1968 [40] after 13, 66 and 129 days of storage since it is used as a flour freshness indicator. Finally, the peroxide index, evaluated as an indicator of the rancid degree of the flours, followed the method described by Silva et al. [41] and was assessed after 41, 66 and 129 days of storage. All the tests were performed in duplicate.

\section{Chestnut flour particle size distribution}

\section{Laser diffraction analysis}

Laser diffraction particle size measurements of the chestnut flours were undertaken using a Mastersizer 2000 (Malvern Instruments, UK) at ambient temperature $\left(20^{\circ} \mathrm{C}\right)$. Particle size was calculated on a volume basis using the Malvern ${ }^{\mathrm{TM}}$ Mastersizer 2000 software (version 5.60). The particle size refractive index and particle absorption index used were 1.53 and 0.1 respectively. The refractive index of the water used as the dispersant was 1.33 .

The sample preparation consisted of the flour suspension in a water-tween dispersant solution ( $4 \mathrm{~g}$ of tween in $50 \mathrm{~mL}$ of purified water). $0.9 \mathrm{~g}$ of the flour were weighed and homogenized manually with 2 drops of the dispersant solution. $100 \mathrm{~g}$ of purified water with 10 drops of dispersant solution were also added, being the mixture subjected to sonication (Transonic 460/H, Germany) over $15 \mathrm{~min}$. Individual sample aliquots were added to the equipment "dispersion unit" until the obscuration value was within the range (10-15\%). Particle size measurement procedure was initiated $5 \mathrm{~min}$ after the addition of each aliquot and its sonication, to ensure sample homogenization in the system. Ten repeated measurements were made on each aliquot with 15 s measurement time. This measurement process was repeated three times.

\section{Image analysis}

The particle size distribution of the flours was also evaluated by image analysis, using an optical microscope (Zeiss Stemi 2000-C, Germany). Three different samples were analysed per each flour. The average diameters of at least 50 photographed particles (to ensure a significant sampling), selected randomly, were measured, allowing determining the equivalent particle volume distribution.

\section{Statistical analysis}

The experimental data was treated by one-way ANOVA, using STATISTICA Software V.12.0 [42] (Table 1). Twoway ANOVA with interaction was employed to determine the effects of both storage time and flour process manufacture on the alcoholic acidity and peroxide index of the flours (Table 2). Mean values were compared using the Tukey's honestly significant difference (HSD) test. Differences were considered significant at $P<0.05$.

\section{Results and discussion}

\section{Production of chestnut flours}

Four chestnut flours were produced (RCF, CCF10, CCF30 and CCF50) applying different process configurations. The process yields were compared (Table 1). For RCF, the production yield was $43.6 \pm 1.0 \%$. The losses were evaluated in almost $56.0 \%$, which included material losses in the equipment, rejected coarse flour, as well as the water loss during drying. Nevertheless, considering that fresh chestnuts from Judia and Longal cultivars have high moisture contents, around 53-54\% [31, 32, 43, 44], the observed losses during flour production are quite reasonable. Indeed, these chestnuts are known to contain low levels of ash, crude fat, and crude protein, with high starch and low fibre contents [31, 32].

For CCF flours the production yields were significantly lower compared to the RCF, varying from $20.6 \pm 0.9 \%$ to $38.0 \pm 1.0 \%$, with substantially greater loss yields. It is worthwhile stating that CCF10 showed the most promising yield results and CCF30 the worst ones.

Comparing the drying kinetics of chestnuts (data not shown) and chestnut by-products (at $40{ }^{\circ} \mathrm{C}$ ), it was found that the by-products dried faster, which the main reason could be its smaller particle size. This means that chestnut 
Table 1 Nutritional composition $(\%, \mathrm{db})$ and quality parameters (colour, $\mathrm{a}_{\mathrm{W}}, \mathrm{pH}$ and sedimentation index) of raw (RCF), cooked (CCF10, CCF30 and CCF50) and commercial chestnut flours (MT and MR) (mean value \pm standard deviation)

\begin{tabular}{|c|c|c|c|c|c|c|}
\hline & \multicolumn{4}{|c|}{ Chestnut flours produced from low-value by-products } & \multicolumn{2}{|c|}{$\begin{array}{l}\text { Commercial } \\
\text { chestnut flours }\end{array}$} \\
\hline & $\mathrm{RCF}$ & CCF10 & CCF30 & CCF50 & MT & MR \\
\hline Production yield (\%) & $43.6 \pm 1.0^{\mathrm{d}}$ & $38.03 \pm 1.0^{\mathrm{c}}$ & $20.6 \pm 0.9^{\mathrm{a}}$ & $25.1 \pm 1.2^{\mathrm{b}}$ & - & - \\
\hline \multicolumn{7}{|l|}{ Composition $(\%, \mathrm{db})$} \\
\hline Total solids & $92.87 \pm 0.06^{\mathrm{a}}$ & $93.58 \pm 0.13^{\mathrm{b}}$ & $93.05 \pm 0.15^{\mathrm{a}}$ & $99.52 \pm 0.11^{\mathrm{c}}$ & 88.87 & 90.56 \\
\hline Crude protein & $5.29 \pm 0.02^{c}$ & $4.06 \pm 0.08^{c}$ & $3.86 \pm 0.06^{\mathrm{b}}$ & $3.64 \pm 0.05^{\mathrm{a}}$ & 6.28 & 5.40 \\
\hline Crude fibre & $10.52 \pm 0.25^{\mathrm{a}}$ & $10.90 \pm 1.33^{\mathrm{a}}$ & $9.31 \pm 0.12^{\mathrm{a}}$ & $9.08 \pm 0.99^{\mathrm{a}}$ & 2.55 & 5.32 \\
\hline Ash & $1.67 \pm 0.02^{\mathrm{c}}$ & $1.30 \pm 0.02^{\mathrm{b}}$ & $3.09 \pm 0.04^{\mathrm{d}}$ & $1.12 \pm 0.02 \mathrm{a}$ & 5.63 & 4.44 \\
\hline Crude fat & $2.46 \pm 0.13^{b}$ & $2.86 \pm 0.02^{\mathrm{b}}$ & $2.97 \pm 0.22^{\mathrm{b}}$ & $1.31 \pm 0.35^{\mathrm{a}}$ & 1.82 & 2.36 \\
\hline NFC & $80.06 \pm 0.31^{\mathrm{a}}$ & $80.90 \pm 1.01^{\mathrm{a}}$ & $80.79 \pm 0.15^{\mathrm{a}}$ & $84.87 \pm 0.57^{b}$ & 83.73 & 82.48 \\
\hline \multicolumn{7}{|l|}{ Quality parameters } \\
\hline $\mathrm{L}^{*}$ & $76.30 \pm 0.00^{\mathrm{d}}$ & $74.80 \pm 0.00^{\mathrm{c}}$ & $72.57 \pm 0.05^{\mathrm{b}}$ & $68.93 \pm 0.09^{\mathrm{a}}$ & 89.80 & 77.90 \\
\hline$a^{*}$ & $1.20 \pm 0.16^{\mathrm{a}}$ & $1.73 \pm 0.17^{\mathrm{a}}$ & $3.50 \pm 0.25^{\mathrm{b}}$ & $3.43 \pm 0.13^{\mathrm{b}}$ & -0.67 & 2.70 \\
\hline $\mathrm{b}^{*}$ & $14.63 \pm 0.12^{c}$ & $14.77 \pm 0.05^{\mathrm{c}}$ & $13.37 \pm 0.19^{\mathrm{a}}$ & $13.83 \pm 0.13^{\mathrm{b}}$ & 12.87 & 15.80 \\
\hline $\mathrm{a}_{\mathrm{w}}$ & $0.438 \pm 0.004^{b}$ & $0.433 \pm 0.002^{b}$ & $0.461 \pm 0.009^{b}$ & $0.080 \pm 0.030^{\mathrm{a}}$ & - & 0.46 \\
\hline $\mathrm{pH}$ & $6.13 \pm 0.03^{c}$ & $6.04 \pm 0.03^{\mathrm{b}}$ & $6.06 \pm 0.03^{\mathrm{bc}}$ & $5.73 \pm 0.05^{\mathrm{a}}$ & 5.40 & 5.70 \\
\hline SI (mL) & $17.5 \pm 0.5^{\mathrm{b}}$ & $17.5 \pm 0.5^{\mathrm{b}}$ & $16.0 \pm 1.0^{\mathrm{b}}$ & $13.5 \pm 0.5^{\mathrm{a}}$ & 9.33 & 11.33 \\
\hline
\end{tabular}

$N F C$ nitrogen-free compounds, $S I$ sedimentation index

Different letters in the same line indicates significant statistical differences among chestnut flours $(P<0.05)$
Table 2 Alcoholic acidity and peroxide index of the chestnut flours, produced from raw or cooked chestnut by-products, over storage

\begin{tabular}{lcll}
\hline Chestnut flour & $\begin{array}{l}\text { Storage } \\
\text { time } \\
\text { (days) }\end{array}$ & $\begin{array}{l}\text { Alcoholic acidity }(\mathrm{g} \\
\mathrm{H}_{2} \mathrm{SO}_{4} / 100 \mathrm{~g} \text { of flour, } \\
\mathrm{db})\end{array}$ & $\begin{array}{l}\text { Peroxide index } \\
\left(\mathrm{mEq} \mathrm{O}_{2} / \mathrm{kg}\right)\end{array}$ \\
\hline $\mathrm{RCF}$ & 13 & $0.148 \pm 0.002^{\mathrm{dC}}$ & - \\
& 41 & - & $31.06 \pm 1.08^{\mathrm{bA}}$ \\
& 66 & $0.099 \pm 0.003^{\mathrm{dA}}$ & $50.88 \pm 1.24^{\mathrm{cB}}$ \\
& 129 & $0.130 \pm 0.003^{\mathrm{dB}}$ & $75.38 \pm 0.53^{\mathrm{cC}}$ \\
CCF10 & 13 & $0.078 \pm 0.001^{\mathrm{cC}}$ & - \\
& 41 & - & $21.80 \pm 0.37^{\mathrm{aA}}$ \\
& 66 & $0.042 \pm 0.001^{\mathrm{bA}}$ & $19.00 \pm 0.35^{\mathrm{aA}}$ \\
& 129 & $0.054 \pm 0.001^{\mathrm{bB}}$ & $18.97 \pm 0.33^{\mathrm{aA}}$ \\
CCF30 & 13 & $0.065 \pm 0.001^{\mathrm{bA}}$ & - \\
& 41 & - & $59.17 \pm 1.18^{\mathrm{cC}}$ \\
& 66 & $0.081 \pm 0.001^{\mathrm{cB}}$ & $33.13 \pm 0.29^{\mathrm{bA}}$ \\
& 129 & $0.091 \pm 0.002^{\mathrm{cC}}$ & $42.00 \pm 0.47^{\mathrm{bB}}$ \\
CCF50 & 13 & $0.057 \pm 0.002^{\mathrm{aC}}$ & - \\
& 41 & - & $149.63 \pm 1.07^{\mathrm{dB}}$ \\
& 66 & $0.033 \pm 0.001^{\mathrm{aA}}$ & $143.58 \pm 1.01^{\mathrm{dA}}$ \\
& 129 & $0.045 \pm 0.001^{\mathrm{aB}}$ & $206.86 \pm 0.40^{\mathrm{dC}}$ \\
& & &
\end{tabular}

Different small letters represent significant differences $(P<0.05)$ amongst flour types for each storage time. Different capital letters represent significant differences $(P<0.05)$ over storage time for each flour type

flour production using by-products as raw material can be an advantageous alternative in order to decrease the production time and energy costs during drying.

\section{Flour composition}

The nutritional composition of the produced chestnut flours is given in Table 1 . The total solid content values pointed out that RCF $(92.87 \pm 0.06 \%)$ had a significant lower level $(P<0.05)$, followed by CCF30 $(93.05 \pm 0.15)$ and CCF10 (93.58 $\pm 0.13 \%)$. The highest value was found for CCF50 (99.52 $\pm 0.11 \%)$, which could be attributed to the higher cooking time of this flour. A similar trend was reported by Wani et al. [16], where a slighter decrease of the moisture content was observed from native to roasted chestnuts flours (from 10.1 to $9.8 \%$ ). The higher moisture decrease observed in this work, could be tentatively attributed to the fact that all the cooked by-products were reduced to a purée, in higher or smaller extent, thus comprising smaller size particles, which would facilitate the drying process and increase the water level removal. On the other hand, Ahmed and Al-Attar [27] also reported low moisture percentages of dried chestnuts flours (freeze or tray dried), ranging from 1.4 to $3.4 \%$. Although the chestnut flour composition is not yet regulated, the maximum allowed moisture content for wheat, maize or rice flours is $14.5 \%$ [45], which means a minimum of $85.5 \%$ of total solid content. Therefore, the chestnut flours obtained would fulfil this legal requirement. Furthermore, the total solids content of the produced flours was higher compared to those determined for two commercial chestnut flours $(88.87 \%$ and $90.56 \%)$, showing that the proposed valorisation of chestnut by-products may be technically feasible. Moreover, the total solids content of all produced 
flours from by-products were also higher compared to that reported for wheat flours $(\sim 87.6 \%, \mathrm{db})[46]$.

Regarding to crude protein levels, the cooked flours CCF10, CCF30 and CCF50 (4.06 $\pm 0.08 \%, 3.86 \pm 0.05 \%$ and $3.64 \pm 0.05 \%, \mathrm{db})$ showed similar contents $(P>0.05)$ and statistically lower than RCF $(5.29 \pm 0.02 \%$, db), pointing out that the cooking process and time may contribute to a greater protein loss. The protein content is a key parameter concerning the possible technological exploitation of chestnut flour and has been reported to be in the range of $6-7 \%$ (db) [26, 28, 47, 48]. Nevertheless, the protein content found for RCF is in agreement with those reported for Judia and Longal raw chestnuts $(4.87-7.29 \%$, db) [31, 32, 43, 44], higher than values reported for flours from different Italian chestnut cultivars (3.7-4.9\%, db) [24], but smaller than for boiled $(5.93-7.01 \%, \mathrm{db})$ or roasted chestnuts $(5.67-7.84 \%$, db) [31], as well as to the values found, in this study, for commercial chestnut flours $(5.40 \%$ and $6.28 \%, \mathrm{db})$.

Concerning the crude fibre content, flours CCF10 and RCF showed the highest levels $(10.90 \pm 1.33 \%$ and $10.52 \pm 0.25 \%, \mathrm{db})$, comparing with CCF30 and CCF50 flours $(9.31 \pm 0.11 \%$ and $9.08 \pm 0.99 \% \mathrm{db}$, respectively). Contrary, Gonçalves et al. [31] found that boiling and roasting procedures would increase the fibre content (soluble, insoluble and total fibre levels) of raw chestnuts. It was also found that the percentage of crude fibres in the flours produced from chestnut by-products is substantially higher than those reported for fresh chestnuts of Judia and Longal cultivars $(2-4 \%, \mathrm{db})[32,43,44]$, and those found in commercial chestnut flours (ranging from $2.55 \%$ and $5.32 \%, \mathrm{db}$ ) or reported by Moreira et al. [26] $(4.52-4.63 \%, \mathrm{db})$. Nevertheless, of the same order of magnitude of those reported by Gonçalves et al. [31].

The raw and cooked flours showed ash contents from $1.12 \pm 0.02 \%$ to $3.09 \pm 0.04 \%$ (db), being the higher value observed for CCF30. The mineral concentration for RCF, CCF10 and CCF50 are of the same order of magnitude of those reported in the literature for raw Judia and Longal chestnuts $(1.6-2.3 \%, \mathrm{db})[31,32,43,44]$ as well as for boiled or roasted chestnuts $(1.7-2.2 \%, \mathrm{db})$ [31]. When compared to the ash content found in commercial chestnut flours $(4.44-5.63 \%, \mathrm{db})$ are a quite lower, although more similar to the contents reported for wheat flours $(\sim 0.34 \%, \mathrm{db})[46]$. The Portuguese legislation establishes maximum ash levels in different flours types, ranging from 0.5 to $2.5 \%$ (db), although no reference is made for chestnut flour. Even so, considering RCF and CCF ash values, just CCF30 is out of the legal thresholds.

Finally, the crude fat contents of RCF, CCF10 and $\mathrm{CCF} 30$ are very similar (ranging from $2.46 \pm 0.12 \%$ to $2.97 \pm 0.22 \%, \mathrm{db})$ respectively, and greater than that of CCF50 $(1.31 \pm 0.35 \%, \mathrm{db})$. The lower content found in CCF50 may be a consequence of the cooking time that lead to higher fat oxidation, which would explain the rancidity odour perceived in this flour. Overall, the fat contents of the produced flours are similar to the crude fat levels reported for Judia and Longal fresh, boiled or roasted chestnuts $(1.6-3.2 \%$, db) [26, 31, 32, 43, 44, 49], and of the same order of magnitude of that found for commercial chestnut flours evaluated in this study (1.8\% and $2.4 \%$, db). However, flours obtained from different Italian chestnut cultivars, showed slightly higher fat contents $(3.6-4.8 \%$, db) [24].

\section{Quality parameters of flours obtained from chestnut by-products}

Colour (CIE L*a*b* coordinates), $\mathrm{a}_{\mathrm{w}}, \mathrm{pH}$ and sedimentation index of RCF and CCF were assessed (Table 1).

The colour of the flour is a decisive parameter for the consumers' acceptance of the final product. This characteristic is highly influenced by processing conditions and procedures. Wani et al. [16] reported that roasting treatment prior to chestnuts consumption not only improve their flavour but also their colour. Moreira et al. [26] pointed out that the colour parameters of chestnut flours showed significant changes with the drying conditions. In this work, colour analysis showed that flour brightness $\left(\mathrm{L}^{*}\right)$ significantly decreases $(P<0.05)$ from uncooked $(76.3 \pm 0.00)$ to cooked $(68.93 \pm 0.09-74.80 \pm 0.00)$ chestnut by-products, as well as with the increasing cooking time $\left(\mathrm{L}^{*}{ }_{\mathrm{CCF} 10}>\right.$ $\left.\mathrm{L}^{*}{ }_{\mathrm{CCF} 30}>\mathrm{L}_{\mathrm{CCF} 50}, P<0.05\right)$. A similar brightness decrease trend was observed from raw to pan and microwave roasted chestnut flours [16], although the $\mathrm{L}^{*}$ values reported (ranging from 90.66 to 81.43 for raw and roasted flours) were substantially higher than those found in the present work. Moreira et al. [26] also concluded that increasing chestnut drying temperature significantly decrease the lightness of the produced flours [from 80.42 (at $85{ }^{\circ} \mathrm{C}$ ) to 74.11 (at $\left.45^{\circ} \mathrm{C}\right)$ ]. In fact, it has been reported that light transmittance decreases with the extent of flour cooking [17]. Also, the $\mathrm{L}^{*}$ values of the flours obtained from the chestnut byproducts were lower than those observed for the commercial chestnut flours evaluated in this work (77.90-89.80) as well as to those reported by Ahmed and Al-Attar [27] for dried chestnuts flours $(\sim 82.0$ to 82.6$)$ or by Torres et al. [50] ( 88.7), and quite lower compared to those reported for wheat flour (91.10) [46], corn flour [51] or rice flour [52]. These results were somehow expected because the chestnut by-products used for chestnut flour production were already darker than high-value chestnuts. An opposite trend was observed for $\mathrm{a}^{*}$ coordinate (green-red coordinate), being the lowest values for flours made from uncooked or minimum cooked by-products (RCF and CCF10), and the highest values (red direction) for the flours made from by-products cooked for longer periods (CCF30 and CCF50). This can be explained by the fact that non-enzymatic redness reactions 
(Maillard reactions) can take place during cooking, and can be favoured by increasing cooking time. A similar behaviour was reported by Wani et al. [16] when evaluating the $a^{*}$ values for raw and pan/microwave roasted chestnut flours (from 0.02 to $0.83-0.90$, respectively). The $a^{*}$ values found for the flours made from by-products are in agreement with the $\mathrm{a}^{*}$ values reported for dried chestnut flours made from the whole fruit (ranging from 3.32 to 4.40) [27], but higher than the reported by Moreira et al. [26] ( -4.1 to 0.3$)$. Torres et al. [50] reported lower a* values $(\sim 1.0)$. For the $\mathrm{b}^{*}$ coordinate (yellow-blue level), the tendency was similar to that detected for $\mathrm{L}^{*}$ coordinate. An opposite trend was observed by Wani et al. [16], which reported an increase of the $b^{*}$ values with the roasting process. The $b^{*}$ values found for the flours produced from chestnut by-products (13.37-14.77) were similar to those observed for chestnut flours obtained from the entire fruit (varying from 13.7 to 19.2) [27] as well as to the values found for the commercial chestnut flours studied (12.87-15.80). Lower $b^{*}$ values $(\sim 5.2,7.16-8.35)$ were reported by Torres et al. [50] and Moreira et al. [26], respectively.

The $\mathrm{a}_{\mathrm{W}}$ of RCF, CCF10 and CCF30 were statistically similar (mean values varying from 0.43 to $0.46, P>0.05$ ), being greater than that observed for CCF50 $(0.08, P<0.05)$, which could be related to the lowest moisture content of this flour. Exception made for CCF50, the $\mathrm{a}_{\mathrm{W}}$ values of the flours produced from chestnut by-products are of the same order of magnitude as that observed for the commercial chestnut flours (0.46). Lastly, regardless the type of chestnut flour, the $a_{w}$ results clearly pointed out its microbiological stability indicating no probability of pathogenic microorganisms' growth, since all the values were significantly lower than 0.5 [53]. In general, most "spoilage" microorganisms are inhibited by $\mathrm{a}_{\mathrm{W}}$ values lower than 0.90 for bacteria, 0.88 for yeast, and 0.80 for moulds [54]. Therefore, taking into account this finding, in this study, the no microbial study was carried out.

The $\mathrm{pH}$ values showed a decrease trend with the cooking time of the chestnut by-products, being the highest $\mathrm{pH}$ observed for RCF $(6.13 \pm 0.03)$ and the lowest for CCF50 $(5.73 \pm 0.05)$. Nevertheless, all the flours obtained from chestnut by-products had $\mathrm{pH}$ greater than 4.6 , meaning that they can be classified as low-acid foods [55].

Similarly, the sedimentation index decreased with the byproducts cooking time $(17.5 \pm 0.50 \mathrm{~mL}$, in the case of RCF and CCF10, $16.0 \pm 1.00 \mathrm{~mL}$ for CCF30 and $13.50 \pm 0.50 \mathrm{~mL}$ for CCF50). Since RCF and CCF10 had the highest sedimentation values, they are expected to possess the best protein quality and baking performance, while CCF50 the poorest. Nevertheless, since the sedimentation index was always lower than $27 \mathrm{~mL}$, the flours obtained from raw or cooked chestnut by-products could be classified as weak flours [56]. According to the values reported for wheat flours [57], flours from chestnut by-products have lower sedimentation indexes, which could be attributed to the absence of gluten. Comparing with commercial chestnut flours $(9.3-11.3 \mathrm{~mL})$ the sedimentation indexes of RCF and CCF were higher.

The alcoholic acidity of each flour was evaluated during its storage (13, 66 and 129 days after production), being the results presented in Table 2. All the analysed flours had almost constant levels of alcoholic acidity during the storage period, being the RCF the one with the highest values (varying from 0.10 to $0.15 \mathrm{~g} \mathrm{H}_{2} \mathrm{SO}_{4} / 100 \mathrm{~g}$, $\mathrm{db}$ ). Moreover, the alcoholic acidity values determined were lower than the maximum legal threshold $\left(0.23 \mathrm{~g} \mathrm{H}_{2} \mathrm{SO}_{4} / 100 \mathrm{~g}\right.$ of flour, db) [45]. Similarly, the flour peroxide indexes over storage (at 41, 66 and 129 days) were also evaluated (Table 2). The highest values were found for CCF50 (varying from $143.57 \pm 0.71$ to $206.86 \pm 0.29 \mathrm{mEq} \mathrm{O}_{2} / \mathrm{kg}$ ) followed by $\mathrm{RCF}, \mathrm{CCF} 30$ and CCF10. High peroxide index values are related to the appearance of rancidity, which was the case of CCF50 being easily perceived a strong stale aroma. Although chestnut flours are not subjected to quality legal requirements for peroxide index, taking into account the maximum thresholds admissible for olive oils $(\leq 20 \mathrm{mEq} \mathrm{O} /$ $\mathrm{kg}$ of oil) $[58,59]$, only the CCF10 would fulfil this requirement ( $<19 \mathrm{mEq} \mathrm{O}_{2} / \mathrm{kg}$ after 66 days of storage). However, it should be noticed that, with the exception of RFC, no obvious increasing trend of the peroxide values was observed with the storage time. Considering that the flours obtained from both raw or cooked chestnut by-products were stored without any lighting or temperature precautions, they presented a satisfactory stability over time. Finally, since the oil content of chestnut is low, the rancid sensation would not be easily perceived in chestnut flours.

\section{Flour particle size distribution}

Laser diffraction was used to characterize the particle size distribution of RCF flour. The results showed that the particles dimensions for this flour, ranged from 2 to $631 \mu \mathrm{m}$, being the particles within 13 and $50 \mu \mathrm{m}$ those that represent the largest equivalent volume in this analysis. Since during the application of this technique was observed that the larger and heavier particles of the flour were not in suspension in the dispersant solution it was concluded that this technique was not the most appropriate to characterizes these samples. Thus, for making a full analysis of all particles of each sample a method based on image analysis was further applied to all flours (Fig. 2). According to this analysis and based on the particle size distribution (volumetric and cumulative curves, not shown), RCF was constituted by particles between 100 and $950 \mu \mathrm{m}$, being those with $650 \mu \mathrm{m}$ responsible for the largest equivalent volume.

The CCF10 contained particles with less than $50 \mu \mathrm{m}$ up to $200 \mu \mathrm{m}$, occupying those with $100 \mu \mathrm{m}$ the largest 
Fig. 2 Optical microscope photographs of chestnut flours obtained from raw or cooked chestnut by-products at different amplifications: RCF flour (a); CCF10 flour (b); CCF30 flour (c); and CCF50 flour (d)
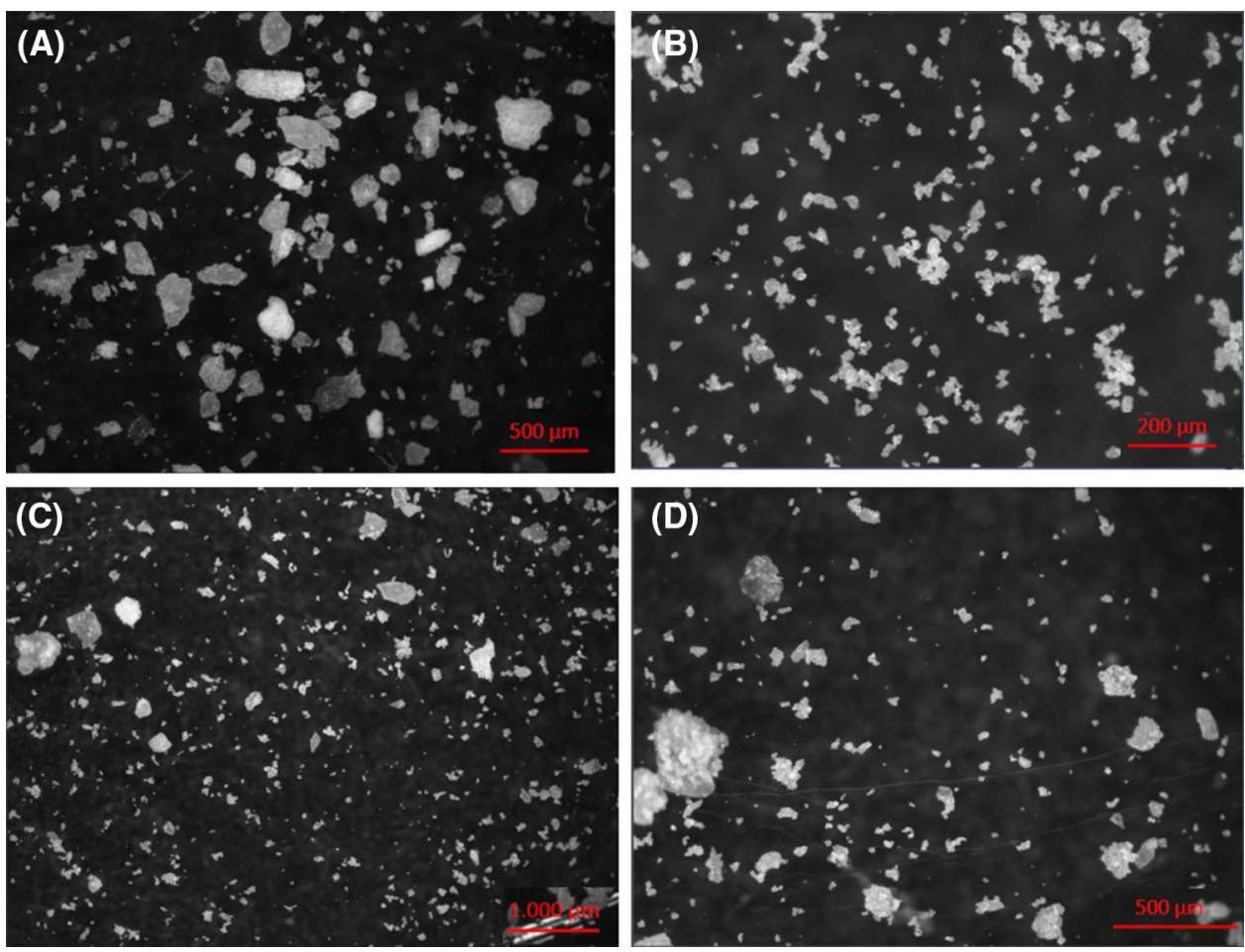

equivalent volume. CCF30 presented a bimodal distribution with the largest equivalent volume for particles with 450 and $550 \mu \mathrm{m}$. The particles size of this flour varied between 101 and $750 \mu \mathrm{m}$. The CCF50 contained particles with less than $50 \mu \mathrm{m}$ up to $400 \mu \mathrm{m}$, being the largest equivalent volume represented by particles with $400 \mu \mathrm{m}$. These results were expected since the cooking step allowed the higher raw material disintegration and the formation of flour smaller particles. In fact, the particle size of the chestnut flour made from raw by-products is conditioned mainly by the grinding process (distance between the grinders, grinding time speed). In the case of the flours made from cooked by-products, the cooking process promoted the reduction of the particles to the size of the starch granules in the chestnut matrix, that is, the size of the flour particles does not depend only on the grinding step. According to Lazaridou et al. [46] wheat flours have smaller particle sizes, usually less than $75 \mu \mathrm{m}$. Also, Morrone et al. [24] reported particle sizes ranging from 16.5 to $91.1 \mu \mathrm{m}$ in flours obtained from dried chestnuts of different Italian cultivars. Torres et al. [50] observed chestnut flour particle sizes ranging from 0.01 to $183 \mu \mathrm{m}$. Moreover, the flours produced from raw or cooked chestnut by-products showed, in general, higher particle sizes in comparison with the commercial chestnut flours, also evaluated in this work, with particle sizes smaller than $106 \mu \mathrm{m}$, which were in agreement with the values found in the literature.

\section{Conclusions}

This study demonstrated that the production of gluten-free chestnut flour from low-value chestnut by-products is a practical way for chestnuts waste valorisation, being a feasible process to increase the economic revenue and the environmental sustainability of the chestnut transformation industry. The use of raw or cooked chestnut by-products will essentially influence the production yield and the granulometry of the final product, with RCF being the most profitable and the cooked chestnut flours the finest. Regarding to the chemical composition, flours made with cooked chestnut by-products had lower protein and fat contents. Aspects such as colour, $\mathrm{a}_{\mathrm{W}}, \mathrm{pH}$ and sedimentation index did not differ significantly among the produced flours, exception made for CCF50. During storage, all the products showed a satisfactory stability, even though the chestnut flour made from 50 min cooked by-products showed quite high peroxide indexes, that can be related to the rancidity perception. Finally, it should be remarked that the particle size range, colour and chemical characteristics of the flours obtained from chestnuts by-products were similar compared with those produced from the whole fruit, showing that the proposed valorisation approach could be foreseen in a near future.

Acknowledgements Part of this work was supported by the program CENTRO2020, under the code 02/SAICT/2016, financed by the Portuguese Government and FEDER. Project $n^{\circ}$ 023631: SoSValor-Sustainable solutions for the valorisation of plant natural products and industrial waste, and by PRODER-Inovação na cadeia de produção da 
castanha: competitividade e sustentabilidade-Medida 4.1, Cooperação para a Inovação, Ref. ${ }^{a}$ 53590. This work was also supported by Project POCI-01-0145-FEDER-006984-Associate Laboratory LSRE-LCM, Project UID/BIO/04469/2013 - CEB and strategic project PEst-OE/ AGR/UI0690/2014-CIMO, all funded by FEDER through COMPETE2020—POCI and by Portuguese funds through FCT.

\section{Compliance with ethical standards}

Conflict of interest The authors declare that they have no conflict of interest.

Ethical approval This article does not contain any studies with human participants or animals performed by any of the authors

Informed consent Not applicable.

\section{References}

1. M.S. Patrício, L. Nunes, iForest 10, 865 (2017)

2. D. Rosa, F. Figueiredo, ÉG. Castanheira, F. Freire, J. Cleaner Prod. 140, 742 (2017)

3. M. Arrobas, S. Afonso, I.Q. Ferreira, J. Moutinho-Pereira, C.M. Correia, M. Rodrigues, Turk. J. Agric. For. 41, 441 (2017)

4. INE (2015). Instituto Nacional de Estatística, Estatísticas Agrícolas 2015, Lisbon, Portugal. https://www.ine.pt/xportal/xmain ?xpid=INE\&xpgid=ine_publicacoes\&PUBLICACOESpub_ boui $=271434407 \&$ PUBLICACOESmodo $=2$. Accessed 13 June 2018

5. N. Braga, F. Rodrigues, M. Beatriz, P.P. Oliveira, Nat. Prod. Res. 29, $1(2015)$

6. T. Delgado, J.A. Pereira, S. Casal, E. Ramalhosa, J. Food Process Eng. 39, 512-520 (2016)

7. I. Rybicka, A. Gliszczyńska-Świgło, J. Nutr. Sci. Vitaminol. 63, 125 (2017)

8. E. Bathrellou, M.D. Kontogianni, D.B. Panagiotakos, Maturitas 112, 29 (2018)

9. N. Aguilar, E. Albanell, B. Miñarro, M. Capellas, Eur. Food Res. Technol. 242, 1795 (2016)

10. I. Demirkesen, J. Food Qual. 39, 264 (2016)

11. M. Paciulli., M. Rinaldi, M. Cirlini, F. Scazzina, E. Chiavaro, LWT Food Sci. Technol. 70, 88 (2016)

12. M. Shafi, W.N. Baba, F.A. Masoodi, R. Bazaz, J. Food Sci. Technol. 53, 4278 (2016)

13. M. Shafi, W.N. Baba, F.A. Masoodi, J. Food Meas. Charact. 11 1094 (2017)

14. I. Kosović, M. Jukić, A. Jozinović, D. Ačkar, D. Koceva, Komlenić, Czech. J. Food Sci. 34, 166-172 (2016)

15. H. Gu, H. Yao, F. Wang, J. Food Process. Preserv. 42, e13364 (2018)

16. I.A. Wani, H. Hamid, A.M. Hamdani, A. Gani, B.A. Ashwar, J. Adv. Res. 8, 399 (2017)

17. S.P. Patil, S.S. Arya, J. Food Meas. Charact. 11, 1284 (2017)

18. F. Boscaino, G. Cammarota, A. Ottombrino, M. Nazzaro, F. Siano, M.G. Volpe, A. Sorrentino, J. Food Process. Preserv. 41, e13013 (2017)

19. T. Ozcan, L. Yilmaz-Ersan, A. Akpinar-Bayizit, B. Delikanli, J. Food Process. Preserv. 41, e13156 (2017)

20. M. Rinaldi, M. Paciulli, A. Caligiani, F. Scazzina, E. Chiavaro, Food Chem. 224, 144 (2017)

21. D. Šoronja-Simović, B. Pajin, D. Šubarić, L. Dokić, Z. Šereš, I. Nikolić, J. Food Process. Preserv. 41, e12887 (2017)
22. F. Zhu, Food Bioprocess. Technol. 10, 1173 (2017)

23. S.A. Mir, S.J.D. Bosco, M.A. Shah, J. Saudi Soc. Agric. Sci., in press (2017) https://doi.org/10.1016/j.jssas.2017.02.002

24. L. Morrone, C. Dall'Asta, A. Silvanini, M. Cirlini, D. Beghè, A. Fabbri, T. Ganino, Sci. Hort. 192, 132 (2015)

25. I. Demirkesen, B. Mert, G. Sumnu, S. Sahin, J. Food Eng. 101, 329 (2010)

26. R. Moreira, F. Chenlo, M.D. Torres, B. Rama, S. Arufe, Int. Food Res. J. 22, 407 (2015)

27. J. Ahmed, H. Al-Attar, Food Hydrocoll. 51, 76 (2015)

28. R. Moreira, F. Chenlo, M.D. Torres, B. Rama, Food Bioprod. Process. 91, 7 (2013)

29. S. Otles, I. Selek, Qual. Assur. Saf. Crop. Foods 4, e3 (2012)

30. F. Zhu, Food Bioprocess. Technol. 9, 1429 (2016)

31. B. Gonçalves, O. Borges, H.S. Costa, R. Bennett, M. Santos, A.P. Silva, Food Chem. 122, 154 (2010)

32. M.D. De Vasconcelos, R.N. Bennett, E.A. Rosa, J.V. Cardoso, J. Agric. Food Chem. 55, 3508 (2007)

33. P. Correia, M.L. Beirão-Da-Costa, Food Bioprod. Process. 90, 284 (2012)

34. A. Frati, D. Landi, C. Marinelli, G. Gianni, L. Fontana, M. Migliorini, F. Pierucci, M. Garcia-Gil, E. Meacci, Food Funct. 5, 2870 (2014)

35. AOAC. Official Methods of Analysis of the AOAC, 16th edn. (AOAC, Arlington, 1997)

36. AOAC (2005). Official Methods of Analysis of the AOAC (Method 979.09-Proteins in Grains). Final action 1994

37. AOAC. Official Methods of Analysis of the AOAC (Method 920.39, C). (AOAC, Arlington, 1995)

38. F.L. Hart, H.J. Fisher, Modern Food Analysis (Springer-Verlag, New York, 1971)

39. ISO 5529:2007 (2007). Wheat-determination of the sedimentation index-Zeleny test. 3rd edn, Reference number ISO 5529:2007(E), $12 \mathrm{pp}$

40. IS:1155-1968 (1990). Indian Standard "Specification for wheat atta", Food and Agriculture Department of India, 2nd revision amended on 3rd of March 1990, New Delhi, India

41. R.C. Silva, L.M. Pino, M.H. Spoto, M.A. D'arce, Food Sci. Technol. 30, 406 (2010)

42. I. StatSoft (2013). STATISTICA, v. 12: Electronic Version Statistics Textbook. Tulsa, OK: StatSoft. WEB: http://www.statsoft. com/textbook/

43. O.P. Borges, B. Gonçalves, J.L.S. Carvalho, P. Correia, A.P. Silva, Food Chem. 3, 976 (2008)

44. J.C.M. Barreira, S. Casal, I.C.F.R. Ferreira, A.M. Peres, J.A. Pereira, M.B.P.P. Oliveira, Food Chem. Toxicol. 50, 2311 (2012)

45. Portaria, $\mathrm{n}^{\circ} 254 / 2003$ de 19 de Março, Diário da República - I Série B, pp. 1861-1864 (2003)

46. A. Lazaridou, D.G. Vouris, P. Zoumpoulakis, C.G. Biliaderis, Food Hydrocoll. 80, 111 (2018)

47. G. Sacchetti, G.G. Pinnavaia, E. Guidolin, M.D. Rosa, Food Res. Int. 37, 527 (2004)

48. R. Moreira, F. Chenlo, M.D. Torres, D.M. Prieto, Food Bioprocess Technol. 5, 2301 (2012)

49. O.P. Borges, J.S. Carvalho, P.R. Correia, A.P. Silva, J. Food Compos. Anal. 20, 80 (2007)

50. M.D. Torres, R. Moreira, F. Chenlo, M.H. Morel, C. Barron, Food Technol. Biotechnol. 52, 135 (2014)

51. K.S. Sandhu, N. Singh, N.S. Mahli, Food Chem. 101, 938 (2007)

52. A. Torbica, M. Hadnađev, T.D. Hadnađev, Food Res. Int. 48, 277 (2012)

53. M.S. Rahman, Handbook of Food Preservation, 2nd edn. (CRCPress Taylor \& Francis Group, New York, 2007), p. 461

54. D.J. Brooker, in Tortillas-Wheat Flour and Corn Products, ed. by L.W. Rooney (S.O. Serna-Saldivar (AACC International Press, New York, 2015), p. 97 
55. Y.B. Tola, H.S. Ramaswamy, J. Food Eng. 116, 900 (2013)

56. E.M. Guarenti, Qualidade Industrial de Trigo, 2nd edn. (EMBRAPA-CNPT, Passo Fundo, 1996)

57. J. Huen, J. Börsmann, I. Matullat, L. Böhm, F. Stukenborg, M. Heitmann, E. Zannini, E.K. Arendt, Eur. Food Res. Technol. 244, 535 (2017)

58. EU No 61, 2011, Commission Regulation of 24 January 2011 amending Regulation No 2568/91/EEC on the characteristics of olive oil and olive pomace oil and on the relevant methods of analysis. Off. J. Eur. Union L23, 1-13 (2011)

59. EU No 1348, 2013. Commission implementing regulation of 16 December 2013 amending Regulation No 2568/91/EEC on the characteristics of olive oil and olive residue oil and on the relevant methods of analysis. Off. J. Eur. Union L338, 31-67 (2013) 